\title{
Diversity and spoilage potential of microbial communities associated with grape sour rot in eastern coastal areas of China
}

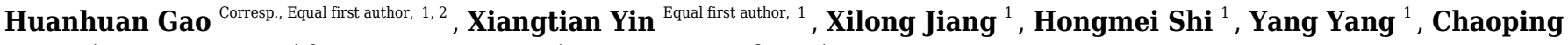 \\ Wang $^{1}$, Xiaoyan Dai ${ }^{1,2}$, Yingchun Chen ${ }^{1}$, Xinying Wu ${ }^{\text {Corresp. } 1}$ \\ ${ }^{1}$ Shandong Academy of Grape, Jinan, China \\ 2 Shandong Academy of Agricultural Sciences, Institute of Plant Protection, Jinan, China \\ Corresponding Authors: Huanhuan Gao, Xinying Wu \\ Email address: gaohuanhuan368@126.com, echomoon0622@163.com
}

As a polymicrobial disease, sour rot decreases grape berry yield and wine quality. The diversity of microbial communities in sour rot-affected grapes depends on the cultivation site, but the microbes responsible for this disease in eastern coastal China, has not been reported. To identify the microbes that cause sour grape rot in this important grape-producing region, the diversity and abundance of bacteria and fungi were assessed by metagenomic analysis and cultivation-dependent techniques. A total of 15 bacteria and 10 fungi were isolated from sour rot-affected grapes. High-throughput sequencing of PCRamplicons generated from diseased grapes revealed 1343 OTUs of bacteria and 1038 OTUs of fungi. Proteobacteria and Firmicutes were dominant phyla among the 19 bacterial phyla identified. Ascomycota was the dominant fungal phylum and the fungi Issatchenkia terricola, Colletotrichum viniferum, Hanseniaspora vineae, Saprochaete gigas, and Candida diversa represented the vast majority ofmicrobial species associated with sour rot-affected grapes. An in vitro spoilage assay confirmed that four of the isolated bacteria strains (two Cronobacter species, Serratia marcescens and Lysinibacillus fusiformis) and five of the isolated fungi strains (three Aspergillus species, Alternaria tenuissima, and Fusarium proliferatum) spoiled grapes. These microorganisms, which appear responsible for spoiling grapes in eastern China, appear closely related to microbes that cause this plant disease around the world. 


\section{Diversity and spoilage potential of microbial}

\section{2 communities associated with grape sour rot in eastern}

\section{3 coastal areas of China}

4

5 Huanhuan $\mathrm{Gao}^{1,2^{*}}$, Xiangtian Yin ${ }^{1}$, Xilong Jiang ${ }^{1}$, Hongmei Shi ${ }^{1}$, Yang Yang ${ }^{1}$, Chaoping Wang ${ }^{1}$,

6 Xiaoyan Dai ${ }^{1,2}$, Yingchun $\mathrm{Chen}^{1}$, XinYing $\mathrm{Wu}^{1 *}$

7

8 Huanhuan Gao and Xiangtian Yin contributed equally to this work

9

${ }^{1}$ Shandong Academy of Grape, Jinan, 250100, China

${ }^{2}$ Institute of Plant Protection, Shandong Academy of Agricultural Sciences, Jinan, 250100, China

13 Corresponding author:

14 Huanhuan Gao

15 Shandong Academy of Grape, 3666 East Second Ring Road, Jinan, 250100

16 E-mail: gaohuanhuan368@126.com

17 XinYing $\mathrm{Wu}$

18 Shandong Academy of Grape, 3666 East Second Ring Road, Jinan, 250100

19 E-mail: echomoon0622@163.com 


\section{Abstract}

23 As a polymicrobial disease, sour rot decreases grape berry yield and wine quality. The diversity

24 of microbial communities in sour rot-affected grapes depends on the cultivation site, but the

25 microbes responsible for this disease in eastern coastal China, has not been reported. To identify

26 the microbes that cause sour grape rot in this important grape-producing region, the diversity and

27 abundance of bacteria and fungi were assessed by metagenomic analysis and cultivation-

28 dependent techniques. A total of 15 bacteria and 10 fungi were isolated from sour rot-affected

29 grapes. High-throughput sequencing of PCR-amplicons generated from diseased grapes revealed

301343 OTUs of bacteria and 1038 OTUs of fungi. Proteobacteria and Firmicutes were dominant

31 phyla among the 19 bacterial phyla identified. Ascomycota was the dominant fungal phylum and

32 the fungi Issatchenkia terricola, Colletotrichum viniferum, Hanseniaspora vineae, Saprochaete

33 gigas, and Candida diversa represented the vast majority of microbial species associated with

34 sour rot-affected grapes. An in vitro spoilage assay confirmed that four of the isolated bacteria

35 strains (two Cronobacter species, Serratia marcescens and Lysinibacillus fusiformis) and five of

36 the isolated fungi strains (three Aspergillus species, Alternaria tenuissima, and Fusarium

37 proliferatum) spoiled grapes. These microorganisms, which appear responsible for spoiling

38 grapes in eastern China, appear closely related to microbes that cause this plant disease around

39 the world.

40

41 Introduction

42 Grape sour rot is a polymicrobial disease characterized by the disaggregation of the internal

43 tissues of berries, detachment of the rotten berry from the pedicel, and a strong ethyl acetate

44 smell. This disease causes millions of dollars in revenue loss each year due to decreases in the

Peer] reviewing PDF | (2019:05:37985:11:0:NEW 6 May 2020) 
45 quality of berries (Barata et al., 2011; Steel, Blackman \& Schmidtke, 2013). A number of

46 microorganisms, such as Ascomycota, acetic acid bacteria (AAB), and filamentous fungi, can

47 infect ripe and thin-skinned grape berries (Nally et al., 2013). Acetic acid released by AAB

48 attracts the fruit fly Drosophila, which contributes to sour rot (Hall et al., 2018). The composition

49 of microorganisms in sour rot-affected grapes depends on the cultivation site and grape variety.

50 The frequency and density of yeast species associated with sour rot differ between grape

51 cultivars. The most frequently recovered ascomycetous species from rotten wine grapes are

52 Candida krusei, Kloeckera apiculata, and Metschnikowia pulcherrima and a less frequent

53 species is Issatchenkia occidentalis (Guerzoni \& Marchetti, 1987). Barata et al. (2008) reported

54 that Candida vanderwaltii, Hanseniaspora uvarum, and Zygoascus hellenicus are the most

55 frequent species in rotten Trincadeira Preta red grape. The relative abundance of these

56 microorganisms depends on the ripening stage and the availability of nutrients. Basidiomycetes

57 and the yeast-like fungus Aureobasidium pullulans dominate intact grape berries. Ascomycetes

58 with higher fermentative activity, like Pichia spp., Zygoascus hellenicus, wine spoilage yeasts,

59 and $\mathrm{AAB}$, are more frequent in rotten grape samples than in healthy grapes (Barata, Malfeito-

60 Ferreira \& Loureiro, 2012a; Barata, Malfeito-Ferreira \& Loureiro, 2012b). Other than the

61 widespread Hanseniaspora uvarum in sour rot wine grapes and table grapes, non-saccharomyces

62 yeast (NSY) and AAB species occur in sour rot table grape. Pinto et al. (2017) proved that

63 among all NSY-AAB associations, the yeast-bacterium association composed of Candida

64 zemplinina CBS 9494 and Acetobacter syzygii LMG 21419 shows the highest prevalence. This 
67 Advances in molecular biology techniques and metagenomics have facilitated microbial community analyses (Andreote, Azevedo \& Araújo, 2009) and characterization of microbes associated with plant diseases (Huang et al., 2017; Shen et al., 2018; Brady et al., 2017). Hall et

70 al. (2019) characterized the microbiome of sour rot-affected grapes in New York by high-

71 throughput sequencing and found that Acetobacter species were significantly more abundant in

72 symptomatic samples than in asymptomatic ones. Studies of the microbial diversity of bacteria

73 and fungi in rotten grapes in the eastern coast of China, a very important grape growing region,

74 are limited.

75 In this study, metagenomic analysis was used to determine the diversity and abundance of

76 bacteria and fungi in sour rot-affected table grapes collected from Yantai city. In parallel, we

77 isolated several microbes and determined their potential to spoil grapes in an in vitro assay.

78

\section{Materials \& Methods}

\section{Samples of sour rot-affected grapes}

81 Sour rot-affected grapes infested with fruit flies were collected from vineyards in Yantai

$82\left(\mathrm{~N} 36^{\circ} 27^{\prime}, \mathrm{E} 117^{\circ} 10^{\prime}\right)$, Shandong Province, China. Approximately $1.0 \mathrm{~g}$ of rotten tissue was sliced

83 from each sour rot-affected grape (Muscat), and the tissues from 100 sour rot-affected grapes

84 were collected together into one $50-\mathrm{mL}$ sterile centrifuge tube. Three replicates from a total of

85300 sour rot-affected grapes were stored at $-80^{\circ} \mathrm{C}$ for $16 \mathrm{~S}$ rDNA and ITS high-throughput 
86 sequencing. Another three replicates were used for the separation and identification of culturable

87 microorganisms in sour rot-affected grapes.

88 16S rDNA and ITS high-throughput sequencing analysis

89 (1) DNA extraction and Illumina MiSeq sequencing of 16S rDNA and ITS genes

90 DNA was extracted from three rotten group samples using the Insect DNA Kit (OMEGA) and

91 further purified using the MoBio PowerSoil Kit. The bacterial universal primers $341 \mathrm{~F}$ (5'-

92 CCTACACGACGCTCTTCCGATCTN (barcode) CCTACGG-GNGGCWGCAG-3') and 805 R

93 (5'-GACTGGAGTTCCTTGGCACCCGAGAA-

94 -TTCCA (barcode) GACTACHVGGGTATCTAATCC-3') were used for amplification of the

$95 \mathrm{~V} 3-\mathrm{V} 4$ region of $16 \mathrm{~S}$ rDNA. The fungal universal primers ITS4 F (5'-

96 CCCTACACGACGCTCTTCCGATCTN (barcode) TCCTCCGCTTATTGATATG-3') and ITS3

97 R (5'-GTGACTGGAGTTCCTTGG CACCCGAGAATTCCAGCATCGAT-

98 -GAAGAACG--CAGC-3') were used for amplification of the ITS gene. Each reaction comprised

$9915 \mu \mathrm{L}$ of Phurs Mix (2er), $1.5 \mu \mathrm{L}$ of each primer, $10 \mathrm{ng}$ of template DNA, and $\mathrm{ddH}_{2} \mathrm{O}$. The

100 cycling conditions were as follows: initial denaturation at $95^{\circ} \mathrm{C}$ for $1 \mathrm{~min}$, followed by 35 cycles

101 at $95^{\circ} \mathrm{C}$ for $10 \mathrm{sec}, 54^{\circ} \mathrm{C}$ for $30 \mathrm{sec}$, and $72^{\circ} \mathrm{C}$ for $30 \mathrm{sec}$, and a final extension at $72^{\circ} \mathrm{C}$ for $5 \mathrm{~min}$.

102 ITS was amplified under similar cycling conditions, except for the annealing temperature $\left(52^{\circ} \mathrm{C}\right)$.

103 The sequencing libraries for 16S rDNA and ITS were constructed using the TruSeq DNA PCR-

104 Free Preparation Kit (Illumina, San Diego, CA, USA) and quantified using Qubit 3.0 (Life

105 Technologies, Grand Island, NY, USA). Then, the library was sequenced on an Illumina MiSeq

106 platform (HiSeq 2000; PE250). After the removal of low-quality reads and primer/adaptor

107 sequences using SeqClean, high-quality reads (clean data) were generated and used for further 
108 analysis. These sequencing procedures were performed by Sangon Biotech (Shanghai, China)

109 Co., Ltd.

110 (2) Alpha diversity analysis

111 Sequences were clustered into operational taxonomic units (OTUs) using the $97 \%$ identity

112 threshold (3\% dissimilarity level) (Mothur, https://mothur.org/) (Schloss et al., 2009). The reads

113 of 16S rDNA and ITS sequences had been submitted in the Short Read Archive (BioProject ID:

114 PRJNA61015). According to the number of OTUs, the rarefaction curve for 16S rDNA and ITS

115 sequences was made to measure the adequacy and rationality of data. Shannon and Simpson

116 diversity indexes were calculated as indicators of microbial diversity, and Chao1 and ACE

117 indices were calculated as indicators of microbial richness using Mothur (Schloss et al., 2009).

118 All OTUs were analyzed using BLASTN and the 16S rDNA and ITS databases

119 (http://ncbi.nlm.nih.gov/). The best results (similarity $>90 \%$ and coverage $>90 \%$ ) were used for

120 subsequent classification. The sequences that did not satisfy these criteria were defined as

121 “unclassified.” Species richness and relative abundances were estimated.

122 Diversity of culturable microorganisms in sour rot-affected grapes

123 The above samples with three replicates were suspended in phosphate-buffered saline (PBS, 0.2

$124 \mathrm{M}, \mathrm{pH} 7.2)$ at ratios of $1: 10^{3}, 1: 10^{4}$ and $1: 10^{5}$. The suspension (200 $\mu \mathrm{L}$; different concentrations)

125 was spread on nutrient agar medium and potato dextrose agar medium with three replicates each.

126 After culturing at $25^{\circ} \mathrm{C}$ for $48 \mathrm{~h}$ on nutrient agar and $7 \mathrm{~d}$ on potato dextrose agar a total of 80

127 colonies were picked and restreaked for purity using the primary media.

128 (1) Identification of cultivated bacteria

129 Physiological and biochemical characteristics of each bacterium were analyzed according to the 130 methods described by Dong \& Cai (2010). The following tests were performed: Gram staining, 
131 spore staining, bacterial motility test, catalase reaction, methyl red test, starch hydrolysis,

132 benzopyrrole test, VP test, malonic acid test, gelatin test, $\mathrm{H}_{2} \mathrm{~S}$ test, citrate test, ammonia

133 production test, litmus milk test, and urease test.

134 DNA was extracted from a single colony of each bacterium using the Bacterial DNA Kit

135 (OMEGA, Norcross, GA, USA) and purified using the DNA Clean-Up Kit (OMEGA). 16S

136 rDNA was amplified for each DNA template using the Bio-Rad 1000-Series Thermal Cycler

137 PCR (Hercules, CA, USA). The thermal cycling profile was as follows: initial denaturation at $13895^{\circ} \mathrm{C}$ for $3 \mathrm{~min}$, followed by 35 cycles of $95^{\circ} \mathrm{C}$ for $15 \mathrm{sec}, 54^{\circ} \mathrm{C}$ for $30 \mathrm{sec}$, and $72^{\circ} \mathrm{C}$ for $1 \mathrm{~min}$, 139 and a final extension at $72^{\circ} \mathrm{C}$ for $5 \mathrm{~min}$. Primer sequences were as follows: $16 \mathrm{~S}$ rDNA-27F: $5^{\prime}-$ 140 AGAGT TTGATCCTGGCTCAG-3'; 16S rDNA-1492R: 5'-

141 TACGGYTACCTTGTTACGACTT-3'.

142 (2) Identification of cultivated fungi

143 The morphological features of each fungus were analyzed using a light microscope (CX41RF;

144 Olympus, Tokyo, Japan) according to the methods described by Dai (1988). The mycelium of

145 each purified fungus was collected in PDA medium. DNA was extracted using the Fungal DNA

146 Kit (OMEGA) and purified using the DNA Clean-Up Kit (OMEGA). The ITS gene was

147 amplified according to the following thermal cycling profile: initial denaturation at $95^{\circ} \mathrm{C}$ for 3

148 min, quantification for $35 \operatorname{cycles}\left(95^{\circ} \mathrm{C}\right.$ for $15 \mathrm{sec}$ followed by $52^{\circ} \mathrm{C}$ for $30 \mathrm{sec}$ and $72^{\circ} \mathrm{C}$ for 1

$149 \mathrm{~min}$ ), and a final extension at $72^{\circ} \mathrm{C}$ for $5 \mathrm{~min}$. Sequences of the universal primers were as

150 follows: ITS1: 5'-TCCGTAGGTGAACCTGCGG-3'; ITS4: 5'-TCCTCCGCTTATTGATATGC$1513^{\prime}$.

152 (3) Sequencing 
153 PCR products were purified using the TaKaRa Mini BEST Agarose Gel DNA Extraction Kit

154 (Takara, Japan) and sequenced on an ABI-3730 DNA analyzer (Applied Biosystems, Foster

155 City, CA, USA).The sequences were analyzed using BLAST (http://ncbi.nlm.nih.gov/).

156 Phylogenetic trees of bacteria and fungi were separately constructed using the neighbor-joining

157 method (NJ; Saitou and Nei, 1987) implemented in MEGA 6.0 (LynnonBiosoft, San Ramon,

158 CA, USA). The sequences of bacteria and fungi were submitted to GenBank using SEQUIN (see

159 phylogenetic trees for accession numbers).

\section{Spoilage potential assay of cultivated bacteria and fungi}

161 Isolated bacteria and fungi were tested for spoilage potential on grape berries. Healthy grape

162 berries of Midnight Beauty, a susceptible variety, were collected and surface sterilized with $1 \%$

163 sodium hypochlorite $(\mathrm{NaClO})$ solution for one minute. Excess $\mathrm{NaClO}$ was removed by washing

164 the berries twice in sterile distilled water. The experimental berries were pricked 2-3 mm deep

165 using a dissecting needle to simulate the wounds made by fruit flies during egg laying or other

166 mechanical damage. The bacterial suspension and fungal spore suspension were prepared with a

167 concentration of approximately $1 \times 10^{6} \mathrm{cfu} / \mathrm{ml}$ or conidia $/ \mathrm{ml}$ in the suspension. This suspension

168 ( $5 \mu$ l per berry) was used to inoculate the wounds of healthy grape berries. Sterile water was

169 used instead of the suspension as a negative control. Two methods were used to observe the

170 spoilage potential of bacteria and fungi. In the merged placement method, 10 grape berries were

171 placed in a single Petri dish (10 $\mathrm{cm}$ in diameter and $3 \mathrm{~cm}$ in height $)$ to simulate grape clusters in

172 the field. In the separate placement method, each of 10 grape berries was placed in a single 
173 culture bottle $(2.5 \mathrm{~cm}$ in diameter and $3 \mathrm{~cm}$ in height). Three replicates were established for both

174 methods and each bacterium and fungus treatment. Subsequently, the inoculated grape berries

175 were kept in a moisture chamber at $27^{\circ} \mathrm{C} / 25^{\circ} \mathrm{C}$ (day/night) and $80 \%$ humidity, and symptoms

176 were recorded on the 5th day. The bacterial and fungal species were reisolated from these

177 artificially inoculated grape berries using NA medium and PDA medium, respectively. The

178 resulting culture was compared with the original culture (Hyun et al., 2001).

179 Based on the ratio of the infected area to the total area, grading was performed as follows

180 (Rouxel et al., 2013; Zhou et al., 2014): 0, no disease spot; 1, less than 5\% of the total area

181 infected; $3,5 \%$ to $25 \%$ of the total area infected; $5,25 \%$ to $50 \%$ of the total area infected; $7,50 \%$

182 to $75 \%$ of the total area infected; $9,75 \%$ to $100 \%$ of the total area infected. The incidence $(\%)$

183 and the McKinney index of bacteria and fungi were calculated according to the following

184 formulas:

185

186

187

The percentage of incidence $(\%)=100 * \frac{\text { the number of diseased berries }}{\text { the number of all berries }}$

The McKinney index $=100 * \sum_{k=0}^{\mathrm{n}} \frac{k x}{9 N}$

where, $x$ is the value for each grade; $n$ is the number of diseased berries at each level; and $N$ is

190 the total number of fruits investigated.

191

192 Results

193 Sequencing and alpha diversity analyses 
194 The mean lengths of 16S rDNA of bacteria and ITS gene of fungi generated from metagenomic 195 DNA extracted from rotting grapes were $413 \pm 3 \mathrm{bp}$ and $279 \pm 5 \mathrm{bp}$, respectively. The OTU 196 numbers for bacteria and fungi were $1343 \pm 283$ and $1039 \pm 387$ respectively (Table 1 ).

197 Rarefaction curves of three samples for 16S rDNA and ITS sequences reached asymptotes (Fig. 198 S1), which suggests coverage was sufficient. The number of sequences for each OTU decreased 199 rapidly by the OTU rank of 18 (Fig. S1). The flat curve indicated a high degree of sequencing 200 uniformity.

201 In a phylogenetic tree of the top 50 bacterial OTUs, 15 OTUs were classified as phylum 202 Firmicutes, class Bacilli. Among the other 35 Proteobacteria, 21 OTUs belonged to the class 203 Alphaproteobacteria, three to Betaproteobacteria, and 11 to Gammaproteobacteria (Fig. S2). In 204 a phylogenetic tree of the top 50 fungal OTUs, one belonged to Basidiomycota and eight were 205 not identified based on searches against the ITS database. Among the other 41 Ascomycota 206 OTUs, 29 belonged to the class Saccharomycetes, nine to Sordariomycetes, and two to 207 Dothideomycetes (Fig. S3).

208 The microbial diversity, as determined by the Shannon index and Simpson index, was higher for 209 bacteria than fungi, and richness, as determined by the Chao1 index and ACE index, was higher 210 for fungi than bacteria (Table 2).

\section{Microbial taxonomic analysis}

212 Proteobacteria (72\%) and Firmicutes (27\%) were dominant among the 19 bacteria phyla

213 identified (Fig. 1A). The proportion of other bacteria was less than 1\%. The dominant genera in

214 sour rot-affected grapes were Acetobacter (38\%), Gluconobacter (24\%), Bacillus (12\%), and 215 Lactococcus (Fig. 1B). 
216 Ascomycota (94\%) was the dominant phylum in the identified fungal community (Fig. 2A). The

217 dominant species identified in sour rot-affected grapes were Issatchenkia terricola (18\%),

218 Colletotrichum viniferum (13\%), Hanseniaspora vineae (13\%), Saprochaete gigas (4\%), and

219 Candida diversa (4\%), and 32\% of isolates were not taxonomically identified (Incertae sedis sp.)

220 (Fig. 2B).

221 Diversity of culturable microorganisms in sour rot-affected grapes

222 We cultured 15 bacterial strains from sour rot-affected grapes infested by fruit flies (Table 3).

223 We identified Firmicutes as the dominant phylum (60\%), with nine Gram-positive bacteria

224 species (i.e., Staphylococcus saprophyticus, Lactococcus garvieae, Lactobacillus plantarum, two

225 Lysinibacillus species, and four Bacillus species). We also isolated six Gram-negative bacteria

226 species assigned to the phylum Proteobacteria. All bacterial taxa presented positive results in

227 catalase reaction, gelatin, $\mathrm{H}_{2} \mathrm{~S}$, and ammonia production assays whereas they presented negative

228 results for fermentation with the methyl red. Strains classified as Cronobacter malonaticus,

229 Cronobacter sakazakii, and Klebsiella pneumoniae presented negative results for these

230 biochemical tests (Table 4).

231 We cultured ten fungi from sour rot-affected grapes. Five were classified as Deuteromycotina,

232 including Cladosporium oxysporum, Alternaria tenuissima, Geotrichum gigas, Fusarium

233 proliferatum, and Nigrospora sp. (Table 3). C. oxysporum, with bottle-green colonies, developed

234 into conidia by asexual reproduction. A. tenuissima colonies, with a white front side and brown

235 reverse side, developed into conidia in the form of a chain lattice. The hyphae of Saprochaete

236 gigas or Geotrichum gigas, with white colonies, developed into arthrospores by asexual

237 reproduction. F. proliferatum, with red colonies, had branched conidiophores and sickle or long

238 column-shaped conidia. Nigrospora sp. had irregular colonies, branched conidiophores, and ball- 
239 shaped conidia. Five species (i.e., Penicillium citrinum, P. georgiense, Aspergillus niger, A.

240 aculeatus, and A. oryzae) belonged to Ascomycotina. The sporophores of $P$. citrinum and $P$.

241 georgiense grew from hyphae and developed into brush-like structures. These two Penicillium

242 species differed in colony color. The conidia of A. niger, A. aculeatus, and A. oryzae were black,

243 green, and yellow, respectively (Fig. 3).

\section{Spoilage potential of culturable bacteria and fungi for grape sour rot}

245 All 15 bacterial species and 10 fungal species demonstrated the potential to spoil grapes. In the

246 merged placement method, all of the microorganisms except for B. amyloliquefaciens, caused

247 cracking and infection in grapes (Fig. 4A). In the separate placement method, all of fungi except

248 for Saprochaete gigas, could cause infection in grapes. Obvious symptoms were not detected in

249 the grapes treated by bacterium (Fig. 4B). The bacterial species and the fungal species reisolated

250 from these spoiled grapes using NA medium and PDA medium were confirmed as the original

251 microorganisms summarized in Table 3.

252 The incidence and McKinney index of 15 bacterial species and 10 fungal species were

253 significantly different from those of the control (sterile water and LB medium) using the merged

254 placement method (incidence: $F=10.44, P<0.01$; McKinney index: $F=43.28, \mathrm{P}<0.01$; Fig.

255 5A and Fig. 5B). Fungal isolates demonstrated stronger spoilage potential in the grape berries

256 with an incidence of more than $75 \%$. Except for C. oxysporum and P. citrinum, the McKinney

257 index of all other fungi exceeded 50\%, which was greater than that of bacteria. Three Aspergillus

258 species and P. georgiense showed $100 \%$ spoilage on the McKinney index. Healthy grapes were

259 also highly sensitive to $A$. tenuissima and $F$. proliferatum, which high McKinney index values of

$26052 \pm 1$ and $50 \pm 2$, respectively. Among the bacteria, the incidence and McKinney index of two

261 Cronobacter species, Serratia marcescens and Lysinibacillus fusiformis, were higher than those 
262 of the other bacteria. B. amyloliquefaciens and B. cereus led to less serious spoilage than other

263 bacteria (Fig. 4, then Fig. 5). The percentages of incidence and McKinney index of

264 microorganism were lower using separated infection method than merged method, while those of

265 fungi were also higher than bacteria (Percentage of incidence: $F=90.52, P<0.01$; McKinney

266 index: $F=50.49, P<0.01$; Fig. 5C and Fig. 5D). The $C$. oxysporum had the highest spoilage

267 potential among microbial taxa, which was different from the results obtained under merged

268 infection.

269

270 Discussion

271 Metagenomic analysis and culturing indicated that the microorganisms caused spoilage were

272 similar around the world. AAB were the dominant bacteria in rot-affected grapes in eastern

273 coastal areas of China, which is consistent with reports from Australia (Mateo et al., 2014),

274 Portugal (Baratta, Malfeito-Ferreira \& Loureiro, 2012b) and New York (Hall et al., 2019).

275 Aspergillis were the dominant mold, which agrees with reports from Greece (Tjamos et al.,

276 2004) and California (Rooney-Latham et al., 2008). Issatchenkia occidentalis, Hanseniaspora

277 uvarum, and Candida vanderwaltii, Colletotrichum viniferum, and Saprochaete gigas, were also

278 commonly observed, which are the same genera, but different species, than reports from other

279 regions (Guerzoni \& Marchetti, 1987; Barata et al., 2008; Barata, Malfeito-Ferreira \& Loureiro,

280 2012b; Lleixà et al., 2018). Pisani, Nguyen \& Gubler (2015) reported that grape sour rot is a

281 disease complex involving many filamentous fungi and bacteria but is usually initiated by $A$.

282 niger or A. carbonarius in California. We observed similar communities and reported the

283 presence of pathogens, that could infect humans and animals, associated with rotting grapes,

284 such as C. sakazakii SRG2, K. pneumoniae SRG3, and S. gigas SRG18. C. sakazakii is an 
285 emerging opportunistic foodborne pathogen with the potential to cause meningitis, bacteremia,

286 and necrotizing enterocolitis, particularly in infants (Drudy et al., 2006; Aly et al., 2019). K.

287 pneumoniae is an important conditional pathogenic and iatrogenic infectious bacterium.

288 Saprochaete yeasts have emerged as fungal pathogens and causal agents of life-threatening

289 infections in patients with severe neutropenia and hematological malignancies (Pavone et al.,

290 2019). Therefore, sour rotten berries could be a reservoir for human pathogens.

291 Fungal isolates demonstrated greater spoilage potential than bacterial isolates in the grape

292 berries. Except for three Aspergillus species with high McKinney index values, healthy grapes

293 were also sensitive to spoilage fungi (A. tenuissima and $F$. proliferatum) associated with

294 common grape diseases, which was different from studies in other places. As the most common

295 species in the cosmopolitan genus Alternaria, A. tenuissima is found on a broad range of fruit

296 products and causes various diseases, like post-harvest black rot of fruit (Logrieco, Moretti \&

297 Solfrizzo, 2009). Bakshi, Sztejnberg \& Yarden (2001) reported that $F$. proliferatum could also

298 cause the rot of corn, rice, and lily. Therefore, Aspergillus species, A. tenuissima, and F.

299 proliferatum were the main cultivated spoilage fungi causing sour rot in grapes. Among the

300 bacterial isolates, B. amyloliquefaciens and B. cereus led to less serious sour rot in this study.

301 This can possibly be explained by the antibacterial substances generated by B. amyloliquefaciens

302 and B. cereus, which have been used as biological control agents (Risoen, Ronning \& Hegna,

303 2004, Wang et al., 2014). Although L. fusiformis restricts the biofilm formation of some

304 pathogenic bacteria, it caused serious rot in grape berries (Fig. 3). Healthy grapes were sensitive

305 to Cronobacter sp. and S. marcescens, which are spoilage microorganisms (Healy et al., 2010).

306 The spoilage potential assay confirmed that Cronobacter species, $S$. marcescens, and $L$.

307 fusiformis can cause sour rot in grapes. In this study, the incidence and McKinney index of 
308 microorganisms were lower using the separate infection method than using the merged method,

309 further suggesting that diseases related to sour rotten grapes could spread quickly through grape

310 clusters.

311 Sour rot is the culmination of coinfection by various yeasts that convert grape sugars to ethanol

312 and bacteria that oxidize the ethanol to acetic acid (Pinto et al., 2019), and Drosophila spp.

313 mediate these processes (Hall et al., 2018). Sour rot increases attractiveness to ovipositing $D$.

314 melanogaster females and oviposition by D. suzukii facilitates sour rot development (Rombaut et

315 al., 2017; Ioriatti et al., 2018). Furthermore, musts and the beginning of fermentation using rotten

316 Macabeo grapes is consistently characterized by an elevated frequency of Zygosaccharomyces,

317 and $\mathrm{AAB}$ increase in the late stages of fermentation (Lleixà et al. 2018). It is difficult to control

318 sour rot in grapes due to the multiple species associated with this disease. Therefore,

319 relationships among insects, microorganisms, and grapes as well as comprehensive analyses of

320 nosogenesis will be the key question in the researches of sour rot in grapes.

321

322 Conclusions

323 This study identified more spoilage species in sour rot-affected grapes of China using culture-

324 dependent methods combined with high-throughput sequencing analysis, which would provide

325 comprehensive information on targets for the control of the disease. Majority of these microbes

326 could infect grapes with wounds. The microbes associated with sour grape rot in eastern coastal

327 China appear similar to those associated with this disease in vineyards around the world. We

328 reported here that $A$. tenuissima, and $F$. proliferatum spoil grapes. Human and animal pathogens 
329 were also present among the bacteria in sour rot-affected grapes, such as Cronobacter sakazakii,

330 Klebsiella pneumoniae and S. gigas.

331

\section{Acknowledgments}

333 We would like to thank Chao Li for assistance with loading sequences of fungi, Dongyun Qin

334 and Ling Su for assistance with grape collection, and Sha Liu and Dongyun Qin for assistance

335 with the treatment of grape samples.

336

337 References

338 Aly MA, Domig KJ, Kneifel W, Reimhult E. 2019. Whole genome sequencing based

339 comparison of food isolates of Cronobacter sakazakii. Frontiers in Microbiology 10:1464

340 DOI: 10.3389/fmicb.2019.01464.

341

Andreote FD, Azevedo JL, Araújo WL. 2009. Assessing the diversity of bacterial communities associated with plants. Brazilian Journal of Microbiology 40: 417-432 DOI:

344

Bakshi S, Sztejnberg A, Yarden O. 2001. Isolation and characterization of a cold-tolerant strain of Fusarium proliferatum, a biocontrol agent of grape downy mildew. Phytopathology 91:1062-1068 DOI: 10.1094/PHYTO.2001.91.11.1062.

347 10.1590/S1517-83822009000300001.

Barata A, Campo E, Malfeito-Ferreira M, Loureiro V, Cacho J, Ferreira V. 2011. Analytical and sensorial characterization of the aroma of wines produced with sour rotten grapes using GCO and GC-MS: identification of key aroma compounds. Journal of Agricultural and Food 
351 Barata A, Malfeito-Ferreira M, Loureiro V. 2012a. The microbial ecology of wine grape berries.

352 International Journal of Food Microbiology 153: 243-259 DOI:

353 10.1016/j.ijfoodmicro.2011.11.025.

354 Barata A, Malfeito-Ferreira M, Loureiro V. 2012b. Changes in sour rotten grape berry 355 microbiota during ripening and wine fermentation. International Journal of Food Microbiology 154: 152-161 DOI: 10.1016/j.ijfoodmicro.2011.12.029.

357

358

359

360

361

362

363

364

365

366

367

368 369 370

Barata A, Seborro F, Belloch C, Malfeito-Ferreira M, Loureiro V. 2008. Ascomycetous yeast species recovered from grapes damaged by honeydew and sour rot. Journal of Applied Microbiology 104: 1182-1191 DOI: 10.1111/j.1365-2672.2007.03631.x.

Brady C. Arnold D, McDonald J, Denman S. 2017. Taxonomy and identification of bacteria associated with acute oak decline. World Journal of Microbiology \& Biotechnology 33: 143-154 DOI: 10.1007/s11274-017-2296-4.

Dai FL. 1978. Fungal morphology and identification. Beijing: Science Press.

Dong XZ, Cai MY. 2001. Common Bacteria Identification Manual. Beijing: Science Press.

Drudy D, Mullane NR, Quinn T, Wall PG, Fanning S. 2006. Enterobacter sakazakii: an emerging pathogen in powdered infant formula. Clinical Infectious Disease 42: 996-1002 DOI: $10.1086 / 501019$.

Guerzoni E, Marchetti R. 1987. Analysis of yeast flora associated with grape sour rot and of the chemical disease markers. Applied and Environmental Microbiology 53: 571-576 DOI: 10.1016/0167-7799(87)90030-8. 
371 Hall ME, Loeb GM, Cadle-Davidson L, Evans KJ, Wilcox WF. 2018. Grape sour rot: A four-

372 way interaction involving the host, yeast, acetic acid bacteria, and insects. Phytopathology

373 108: 1429-1442 DOI: 10.1094/PHYTO-03-18-0098-R.

374 Hall ME, O’Bryon I, Osier MV. 2019. The epiphytic microbiota of sour rot-affected grapes

375 differs minimally from that of healthy grapes, indicating causal organisms are already

376 present on healthy berries. PLoS One 14: e0211378 DOI: 10.1371/journal.pone.0211378.

377 Healy B,Cooney S, O’Brien S, Iversen C, Whyte P, Nally J, Callanan JJ, Fanning S. 2010.

378 Cronobacter (Enterobacter sakazakii): an opportunistic foodborne pathogen. Foodborne

379 Pathogens and Disease 7: 339-351 DOI: 10.1089/fpd.2009.0379.

380 Huang N, Wang WW, Yao YL, Zhu FX, Wang WP, Chang XJ. 2017. The influence of different

381 concentrations of bio-organic fertilizer on cucumber Fusarium wilt and soil microflora

382 alterations. PLoS ONE 12: e0171490 DOI: 10.1371/journal.pone.0171490.

383 Hyun JW, Timmer LW, Lee SH, Yun SH, Ko SW, Kim KS. 2001. Pathological characterization

384 and molecular analysis of Elsinoe isolates causing scab diseases of citrus in Jeju Island in

385 Korea. Plant disease 85: 1013-1017 DOI: 10.1094/PDIS.2001.85.9.1013.

386 Ioriatti C, Guzzon R, Anfora G, Ghidoni F, Mazzoni V, Villegas TR, Dalton DT, Walton VM.

387 2018. Drosophila suzukii (Diptera: Drosophilidae) contributes to the development of sour

388 rot in grape. Journal of Economic Entomology 111: 283-292 DOI: 10.1093/jee/tox292.

389 Lleixà J, Kioroglou D, Mas A, Portillo MDC. 2018. Microbiome dynamics during spontaneous

390 fermentations of sound grapes in comparison with sour rot and Botrytis infected grapes.

391 International Journal of Food Microbiology 281: 36-46. DOI: 10.1016/j.ijfoodmicro.

392 Logrieco A, Moretti A, Solfrizzo M. 2009. Alternaria toxins and plant diseases: an overview of 
393

394

395

396

397

398

399

400

401

402

403

404

405

406

407

408

409

410

411

412

origin, occurrence and risks. World Mycotoxin Journal 2: 129-140 DOI:

10.3920/WMJ2009.1145.

Mateo E, Torija MJ, Mas A, Bartowsky EJ. 2014. Acetic acid bacteria isolated from grapes of South Australian vineyards. International Journal of Food Microbiology 178: 98-106 DOI: 10.1016/j.ijfoodmicro.2014.03.010.

Nally MC, Pesce VM, Maturano YP, Toro ME, Combina M, Castellanos de Figueroa LI, Vazquez F. 2013. Biocontrol of fungi isolated from sour rot infected table grapes by Saccharomyces and other yeast species. Postharvest Biology and Technology 86: 456-462 DOI: $10.1016 /$ j.postharvbio.2013.07.022.

Pavone P, Oliva A, Raponi G, Pugliese F, Martelli S, Celli P, Sacco F, Vullo V, Mastroianni CM, Russo G. 2019. Disseminated fungal infection due to Saprochaete clavata in a kidney transplant recipient. Journal De Mycologie Medicale 19: S1156-5233 DOI: 10.1016/j.mycmed.2019.06.002.

Pinto L, Caputo L, Quintieri L, de Candia S, Baruzzi F. 2017. Efficacy of gaseous ozone to counteract postharvest table grape sour rot. Food Microbiology 66: 190-198 DOI: 10.1016/j.fm.2017.05.001.

Pinto L, Malfeito-Ferreira M, Quintieri L, Silva A C, Baruzzi F. 2019. Growth and metabolite production of a grape sour rot yeast-bacterium consortium on different carbon sources. International journal of food microbiology 296: 65-74 DOI:

10.1016/j.ijfoodmicro.2019.02.022. 
413 Pisani C, Nguyen TT, Gubler WD. 2015. A novel fungal fruiting structure formed by Aspergillus

$414 \quad$ niger and Aspergillus carbonarius in grape berries. Fungal Biology 119: 784-790 DOI:

$415 \quad$ 10.1016/j.funbio.2015.05.002.

416 Risoen PA, Ronning P, Hegna IK. 2004. Characterization of a broad range antimicrobial

417 substance from Bacillus cereus. Journal of Applied Microbiology 96: 648-655 DOI:

$418 \quad 10.1046 /$ j.1365-2672.2003.02139.x.

419 Rombaut A, Guilhot R, Xuéreb A, Benoit L,Chapuis MP, Gibert P, Fellous S. 2017. Invasive

420 Drosophila suzukii facilitates Drosophila melanogaster infestation and sour rot outbreaks in

421 the vineyards. Royal Society Open Science 4 DOI: 10.1098/rsos.170117.

422 Rooney-Latham S, Janousek CN, Eskalen A, Gubler WD. 2008. First Report of Aspergillus

423 carbonarius causing sour rot of table grapes (Vitisvinifera) in California. The American

424 Phytopathological Society 92: 651-661 DOI: 10.1094/PDIS-92-4-0651A.

425 Rouxel M, Mestre P, Comont G, Lehman BL, Schilder A, Delmotte F. 2013. Phylogenetic and

426 experimental evidence for host-specialized cryptic species in a biotrophic oomycete. New

427 Phytologist 197: 251-263 DOI: 10.1111/nph.12016.

428 Schloss PD, Westcott SL, Ryabin T, Hall JR, Hartmann M, Hollister EB, Lesniewski RA,

429 Oakley BB, Parks DH, Robinson CJ, Sahl JW, Stres B, Thallinger GG, Van Horn DJ,

430 Weber CF. 2009. Introducing mothur: Open-source, platform-independent, community-

431 supported software for describing and comparing microbial communities. Applied and

432 Environmental Microbiology 75: 7537-7541 DOI: 10.1128/AEM.01541-09. 
433 Shen ZZ, Penton CR, Lv N, Xue C, Yuan XF, Ruan YZ, Shen LR, Li R, Shen QR. 2018.

434 Banana Fusarium wilt disease incidence is influenced by shifts of soil microbial

435 communities under different monoculture spans. Microbial Ecology 75: 739-750 DOI:

$436 \quad 10.1007 / \mathrm{s} 00248-017-1052-5$.

437 Steel CC, Blackman JW, Schmidtke LM. 2013. Grapevine bunch rots: impacts on wine 438 composition, quality, and potential procedures for the removal of wine faults. Journal of 439 Agricultural and Food Chemistry 61: 5189-5206 DOI: 10.1021/jf400641r.

440 Tjamos SE, Antoniou PP, Kazantzidou A,Antonopoulos DF, Papageorgiou I, Tjamos EC. 2004.

441 Aspergillus niger and Aspergillus carbonarius in Corinth Raisin and wine-producing

442 vineyards in Greece: population composition, ochratoxin a production and chemical control.

443 Journal of Phytopathology 152: 250-255 DOI: 10.1111/j.1439-0434.2004.00838.x.

444 Wang JJ, Zhao DY, Liu YG, Ao X, Fan R, Duan ZQ, Liu Y. 2014. Antagonism against

445 Beauveria bassiana by lipopeptide metabolites produced by entophyte Bacillus

446 amyloliquefaciens strain SWB16. Acta Microbiologica Sinica 54: 778-785.

447 Zhou TT, Jin GX, Yue YL, Zhang L, Li GY. 2014. Resistance identification of wine grape

448 germplasm to downy mildew. Xinjiang Agricultural Sciences 51: 1845-1850. 


\section{Table 1 (on next page)}

Sequence information of bacterium and fungi in sour rot-affected grapes 
1

Table 1 Sequence information of bacterium and fungi in sour rot-affected grapes

\begin{tabular}{ccccccc}
\hline Group & Sample & $\begin{array}{c}\text { Number of } \\
\text { raw reads }\end{array}$ & $\begin{array}{c}\text { Mean length } \\
\text { of raw reads }\end{array}$ & $\begin{array}{c}\text { Number of } \\
\text { clean reads }\end{array}$ & $\begin{array}{c}\text { Mean length } \\
\text { of clean reads }\end{array}$ & $\begin{array}{c}\text { Number of } \\
\text { filtered reads }\end{array}$ \\
\hline \multirow{4}{*}{ 16S rDNA } & 1 & 56220 & 447 & 54080 & 410 & 38313 \\
& 2 & 63599 & 458 & 61916 & 418 & 39939 \\
& 3 & 52692 & 449 & 51690 & 410 & 24500 \\
\hline \multirow{3}{*}{ ITS } & 1 & 80740 & 317.03 & 80628 & 2746 & 79658 \\
& 2 & 71362 & 332 & 71281 & 2886 & 71160 \\
& 3 & 76531 & 318 & 76432 & 276 & 76154 \\
\hline
\end{tabular}


Table 2 (on next page)

Diversity indices of bacterium and fungi in sour rot-affected grapes 
1

Table 2 Diversity indices of bacterium and fungi in sour rot-affected grapes

\begin{tabular}{cccc}
\hline Parameters & Parameters & Bacterium $($ Mean \pm SE $)$ & Fungi $($ Mean \pm SE $)$ \\
\hline \multirow{3}{*}{ Diversity indices } & Shannon & $3 \pm 1.3$ E-01 & 220 E-2 \pm 1.7 E-01 \\
& ACE & $22034 \pm 2927$ & $32667 \pm 1385$ \\
& Chao1 & $9745 \pm 1430$ & $10779 \pm 1476$ \\
& Simpson & 1 E-01 \pm 2 E-02 & 21 E-2 \pm 4 E-02 \\
\hline \multicolumn{2}{c}{ OTUs number } & $1343 \pm 283$ & $1039 \pm 386$ \\
\hline
\end{tabular}

2 
Table 3 (on next page)

Phylogeny of microbes isolated from sour rot-affected grapes 
1

Table 3 Phylogeny of microbes isolated from sour rot-affected grapes

\begin{tabular}{|c|c|c|c|c|}
\hline Microorganism & Phylum & Species & Strain IDs & $\begin{array}{c}\text { Accession } \\
\text { numbers }\end{array}$ \\
\hline \multirow{15}{*}{ Bacterium } & \multirow{6}{*}{ Proteobacteria } & Cronobacter malonaticus & SRG1 & MK743990 \\
\hline & & Cronobacter sakazakii & SRG2 & MK743989 \\
\hline & & Klebsiella pneumoniae & SRG3 & MK743987 \\
\hline & & Acetobacter sp. & SRG4 & MK743980 \\
\hline & & Serratia marcescens & SRG5 & MK743984 \\
\hline & & Enterobacter hormaechei & SRG6 & MK743988 \\
\hline & \multirow{9}{*}{ Firmicutes } & Staphylococcus saprophyticus & SRG7 & MK743982 \\
\hline & & Lactococcus garvieae & SRG8 & MK743983 \\
\hline & & Lactobacillus plantarum & SRG9 & MK743986 \\
\hline & & Lysinibacillus fusiformis & SRG10 & MK753026 \\
\hline & & Lysinibacillus sp. & SRG11 & MK743985 \\
\hline & & Bacillus amyloliquefaciens & SRG12 & MK743994 \\
\hline & & Bacillus cereus & SRG13 & MK743993 \\
\hline & & Bacillus sp.-1 & SRG14 & MK743992 \\
\hline & & Bacillus sp.-2 & SRG15 & MK743991 \\
\hline \multirow{10}{*}{ Fungus } & \multirow{5}{*}{ Deuteromycotina } & Cladosporium oxysporum & SRG16 & MK748311 \\
\hline & & Alternaria tenuissima & SRG17 & MK748314 \\
\hline & & $\begin{array}{l}\text { Saprochaete gigas or } \\
\text { Geotrichum gigas }\end{array}$ & SRG18 & MN567950 \\
\hline & & Fusarium proliferatum & SRG19 & MK748309 \\
\hline & & Nigrospora sp. & SRG20 & MK748317 \\
\hline & \multirow{5}{*}{ Ascomycotina } & Penicillium citrinum & SRG21 & MK748316 \\
\hline & & Penicillium georgiense & SRG22 & MK748315 \\
\hline & & Aspergillus niger & SRG23 & MK748313 \\
\hline & & Aspergillus oryzae & SRG24 & MK748312 \\
\hline & & Aspergillus aculeatus & SRG25 & MK748310 \\
\hline
\end{tabular}

2

3

4

5

6

7

8

9

10

11 
Table 4 (on next page)

The physiological and biochemical characteristic of bacterium in sour rot-affected grape 
Table 4 The physiological and biochemical characteristic of bacterium in sour rot-affected grape

\begin{tabular}{|c|c|c|c|c|c|c|c|c|}
\hline Bacterium & $\begin{array}{l}\text { Strain } \\
\text { IDs }\end{array}$ & $\begin{array}{c}\text { Gram } \\
\text { staining }\end{array}$ & $\begin{array}{c}\text { Spore } \\
\text { staining }\end{array}$ & $\begin{array}{l}\text { Bacterial } \\
\text { motility }\end{array}$ & $\begin{array}{l}\text { Catalase } \\
\text { reaction }\end{array}$ & Methyl red test & $\begin{array}{c}\text { Starch } \\
\text { hydrolysis test }\end{array}$ & $\begin{array}{c}\text { Benzpyrole } \\
\text { test }\end{array}$ \\
\hline Cronobacter malonaticus & SRG1 & - & & - & + & - & - & - \\
\hline Cronobacter sakazakii & SRG2 & - & & - & + & - & - & - \\
\hline Klebsiella pneumoniae & SRG3 & - & & - & + & - & - & - \\
\hline Acetobacter sp. & SRG4 & - & & + & + & - & - & - \\
\hline Serratia marcescens & SRG5 & - & & + & + & - & + & - \\
\hline Enterobacter hormaechei & SRG6 & - & & + & + & - & + & - \\
\hline Lactococcus garvieae & SRG8 & + & & - & + & - & + & - \\
\hline Lactobacillus plantarum & SRG9 & + & & - & + & - & + & - \\
\hline Lysinibacillus fusiformis & SRG10 & + & purple & + & + & - & + & - \\
\hline Lysinibacillus sp. & SRG11 & + & purple & + & + & - & + & - \\
\hline Bacillus amyloliquefaciens & SRG12 & + & pink & + & + & - & + & - \\
\hline Bacillus cereus & SRG13 & + & purple & + & + & - & + & - \\
\hline Bacillus sp.-1 & SRG14 & & purple & + & + & - & + & - \\
\hline Bacterium & & $\begin{array}{l}\text { Malonic } \\
\text { acid test }\end{array}$ & $\begin{array}{c}\text { Gelatin } \\
\text { test }\end{array}$ & $\mathrm{H}_{2} \mathrm{~S}$ test & Citrate test & $\begin{array}{c}\text { Ammonia } \\
\text { production test }\end{array}$ & Litmus milk test & Urease test \\
\hline Cronobacter malonaticus & SRG1 & - & + & + & + & + & + & - \\
\hline Cronobacter sakazakii & SRG2 & + & + & + & - & + & + & - \\
\hline Klebsiella pneumoniae & SRG3 & + & + & + & + & + & - & + \\
\hline Acetobacter sp. & SRG4 & + & + & + & + & + & + & + \\
\hline Serratia marcescens & SRG5 & + & + & + & - & + & + & - \\
\hline Enterobacter hormaechei & SRG6 & + & + & + & + & + & + & - \\
\hline Staphylococcus saprophyticus & SRG7 & - & + & + & + & + & + & - \\
\hline Lactococcus garvieae & SRG8 & - & + & + & - & + & + & - \\
\hline Lactobacillus plantarum & SRG9 & + & + & + & + & + & + & - \\
\hline
\end{tabular}




\begin{tabular}{|c|c|c|c|c|c|c|c|c|}
\hline Lysinibacillus fusiformis & SRG10 & + & + & + & - & + & - & - \\
\hline Lysinibacillus sp. & SRG11 & + & + & + & + & + & - & - \\
\hline Bacillus amyloliquefaciens & SRG12 & - & + & + & + & + & + & + \\
\hline Bacillus cereus & SRG13 & - & + & + & + & + & + & - \\
\hline Bacillus sp.-1 & SRG14 & + & + & + & + & + & + & + \\
\hline Bacillus sp.-2 & SRG15 & - & + & + & + & + & + & + \\
\hline
\end{tabular}


Figure 1

(A)The bacterial community structure based on genus; (B)The bacterial community structure based on phylum

A

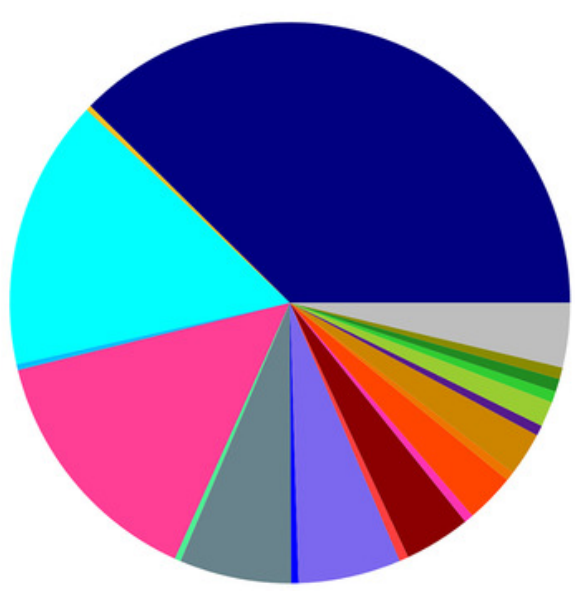

B

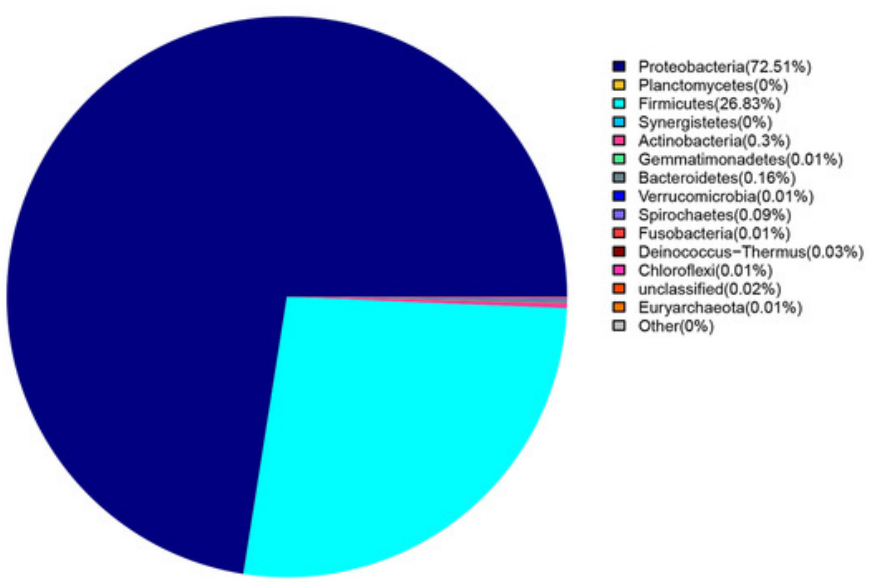




\section{Figure 2}

(A)The fungal community structure based on genus; (B)The fungal community structure based on phylum
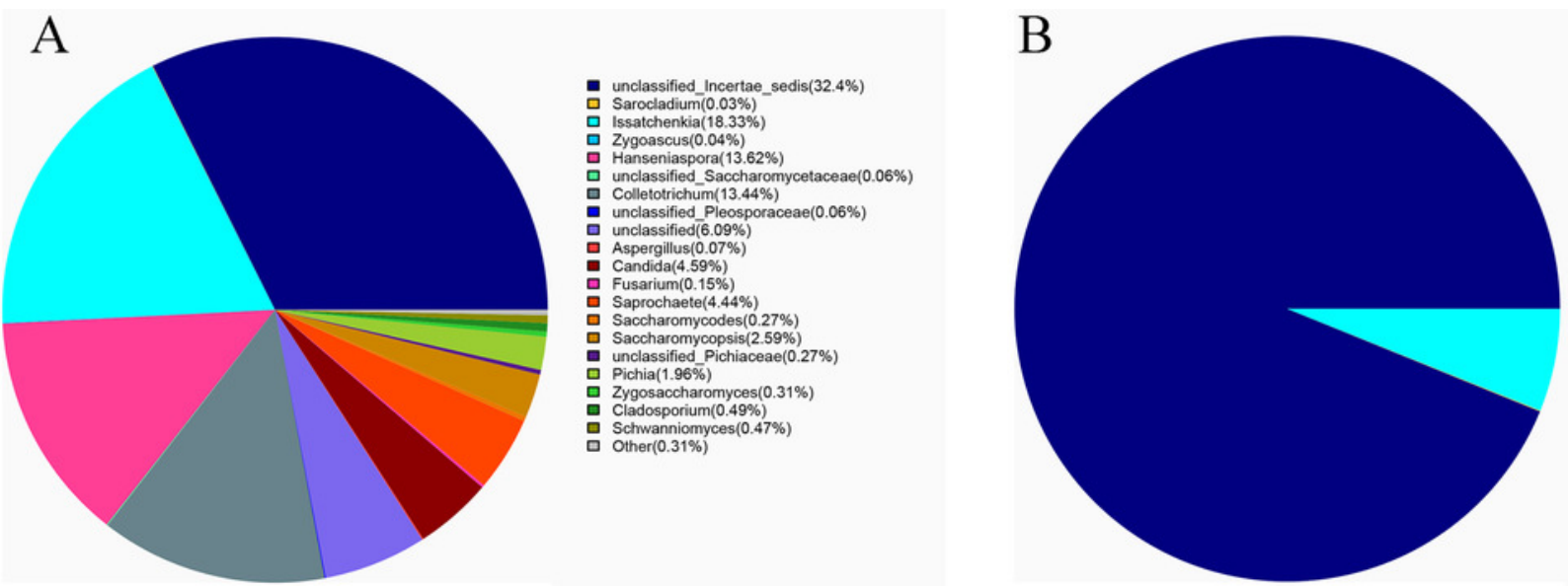

- Ascomycota( $(93.86 \%)$

- unclassified_Incertae_sedis(32.4\%) Sarocladium(0.03\%) Issatchenkia(18.33\%)

Hanseniaspora(13.62\%)

unclassified Saccharomycetaceae $(0.06 \%)$

Colletotrichum(13.44\%)

unclassified_Pleosporaceae $(0.06 \%)$

unclassified(6.09\%)

Fusarium( $0.15 \%)$

Saprochaete(4.44\%) $27 \%$

Saccharomycopsis $(2.59 \%)$

unclassified-Pin)

Zygosacchar

Cladosporium $(0.49 \%)$

Sctwanniomyces $(0.47 \%)$

a Other(0.31\%) 


\section{Figure 3}

The labels of A-E represent the reverse side of colony morphology of Cladosporium oxysporum , Penicillium citrinum, Alternaria tenuissima, Saprochaete gigas, Fusarium proliferatum; The lables of F-J represent the front side of colony morphology of Cladosporium oxysporum, Penicillium citrinum, Alternaria tenuissima, Saprochaete gigas, Fusarium proliferatum; The labels of K-O represent the reverse side of colony morphology of $P$. georgiense, Aspergillus niger, Nigrospora sp., A. oryzae, A. aculeatus; The labels of P-T represent the font side of colony morphology of $P$. georgiense, Aspergillus niger, Nigrospora sp., A. oryzae, $A$. aculeatus. The labels of U-DD represent the light morphology of Cladosporium oxysporum, Alternaria tenuissima, Saprochaete gigas, Fusarium proliferatum, Nigrospora sp., Penicillium citrinum, P. georgiense, Aspergillus niger, A. oryzae, A. aculeatus. 

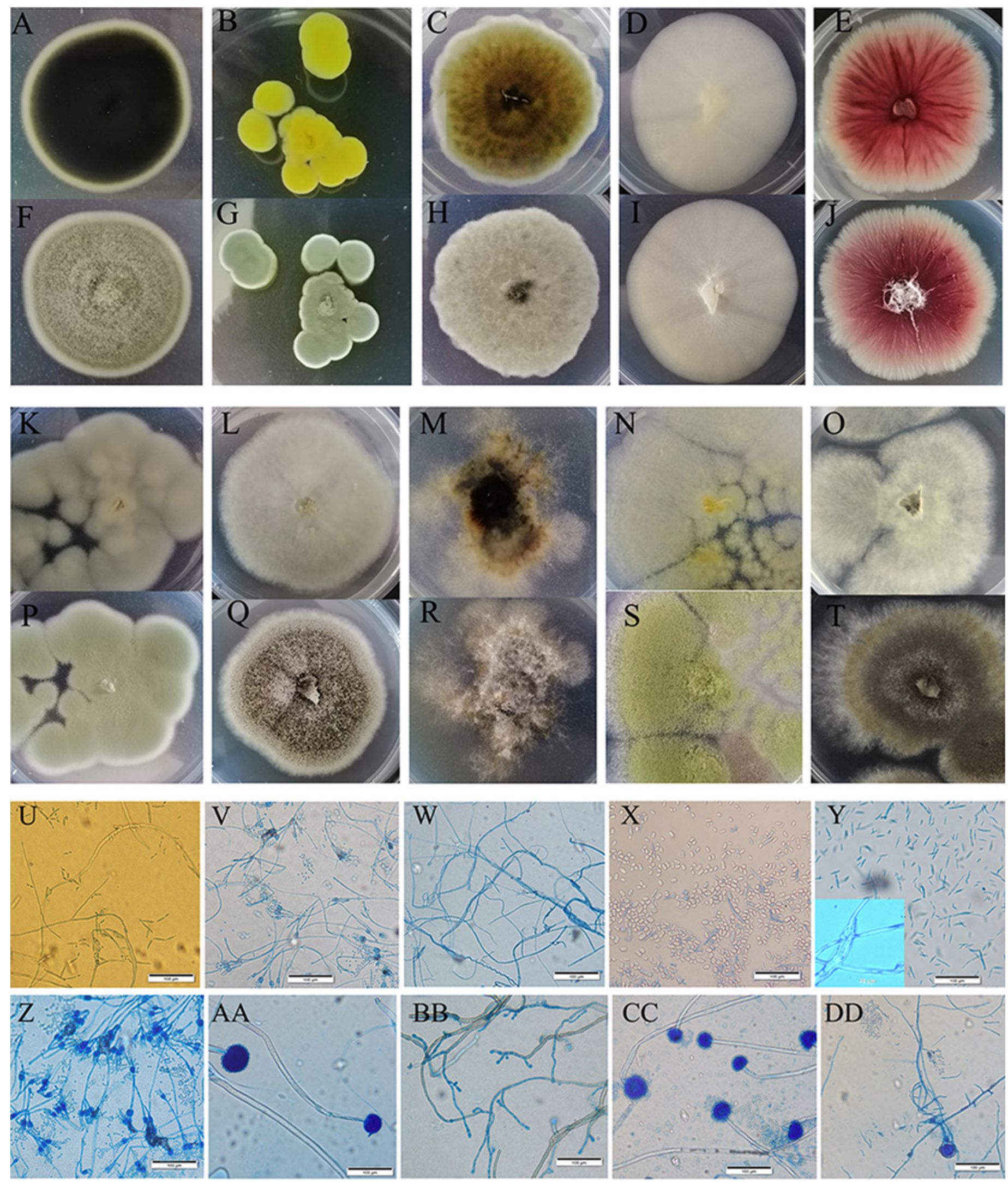


\section{Figure 4}

The labels of A-AA represent pathogenicity of sterile water, LB medium, Cladosporium oxysporum, Alternaria tenuissima, Saprochaete gigas, Fusarium proliferatum, Nigrospora sp., Penicillium citrinum, P. georgiense, Aspergillus niger, A. oryzae, A. aculeatus, Cronobacter malonaticus, C. sakazakii, Klebsiella pneumoniae, Acetobacter sp., Serratia marcescens, Enterobacter hormaechei, Staphylococcus saprophyticus, Lactococcus garvieae, Lactobacillus plantarum, Lysinibacillus fusiformis, Lysinibacillus sp., Bacillus amyloliquefaciens, B. cereus, Bacillus sp.-1, Bacillus sp.-2 using the merged method; The labels of BB-BBB represent pathogenicity of sterile water, LB medium, Cladosporium oxysporum, Alternaria tenuissima, Saprochaete gigas, Fusarium proliferatum, Nigrospora sp., Penicillium citrinum, $P$. georgiense, Aspergillus niger, A. oryzae, A. aculeatus, Cronobacter malonaticus, C. sakazakii, Klebsiella pneumoniae, Acetobacter sp., Serratia marcescens, Enterobacter hormaechei, Staphylococcus saprophyticus, Lactococcus garvieae, Lactobacillus plantarum, Lysinibacillus fusiformis, Lysinibacillus sp., Bacillus amyloliquefaciens, B. cereus, Bacillus sp.-1, Bacillus sp.-2 using the separated method. 

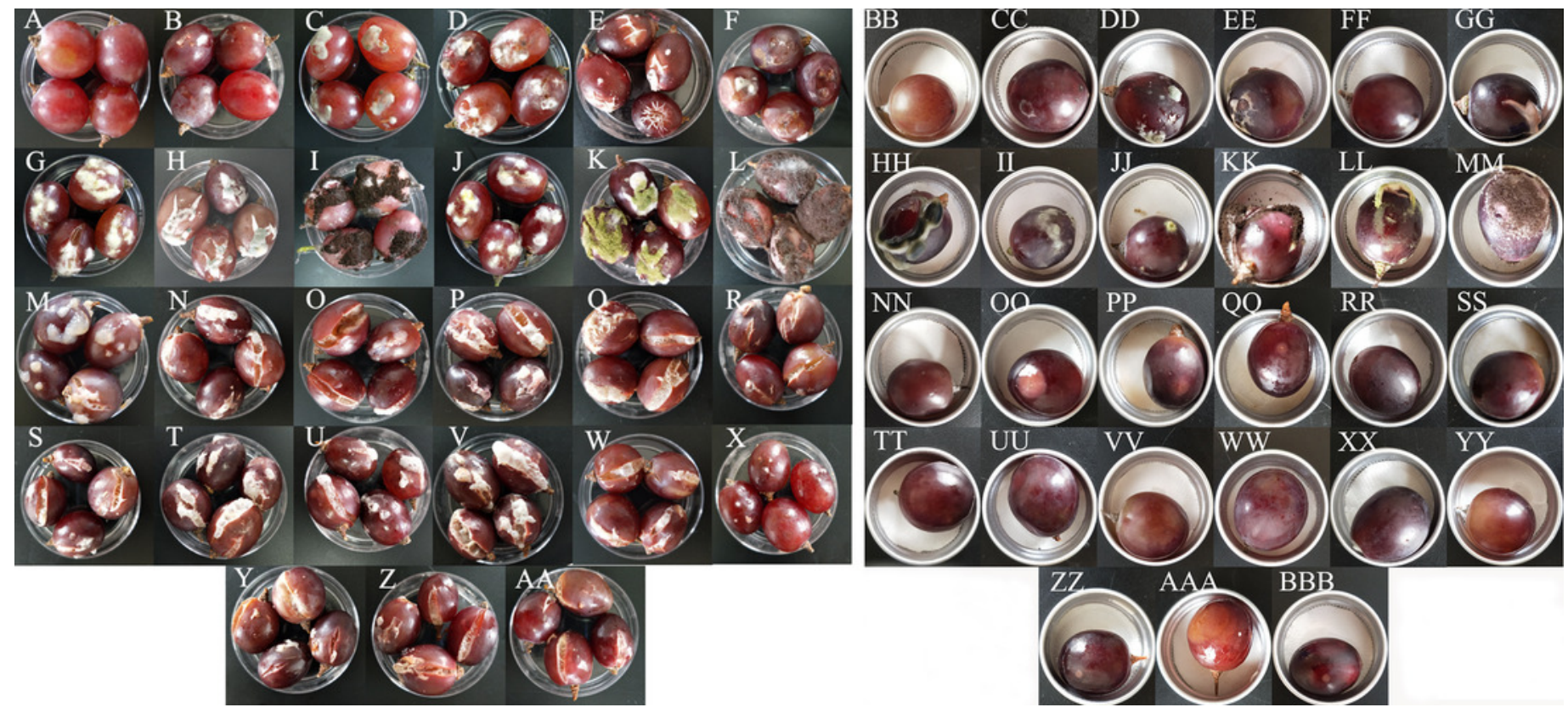
Figure 5

Different letters in each figure indicate significant difference between microorganisms (Oneway ANOVA; $\alpha=0.05$ )
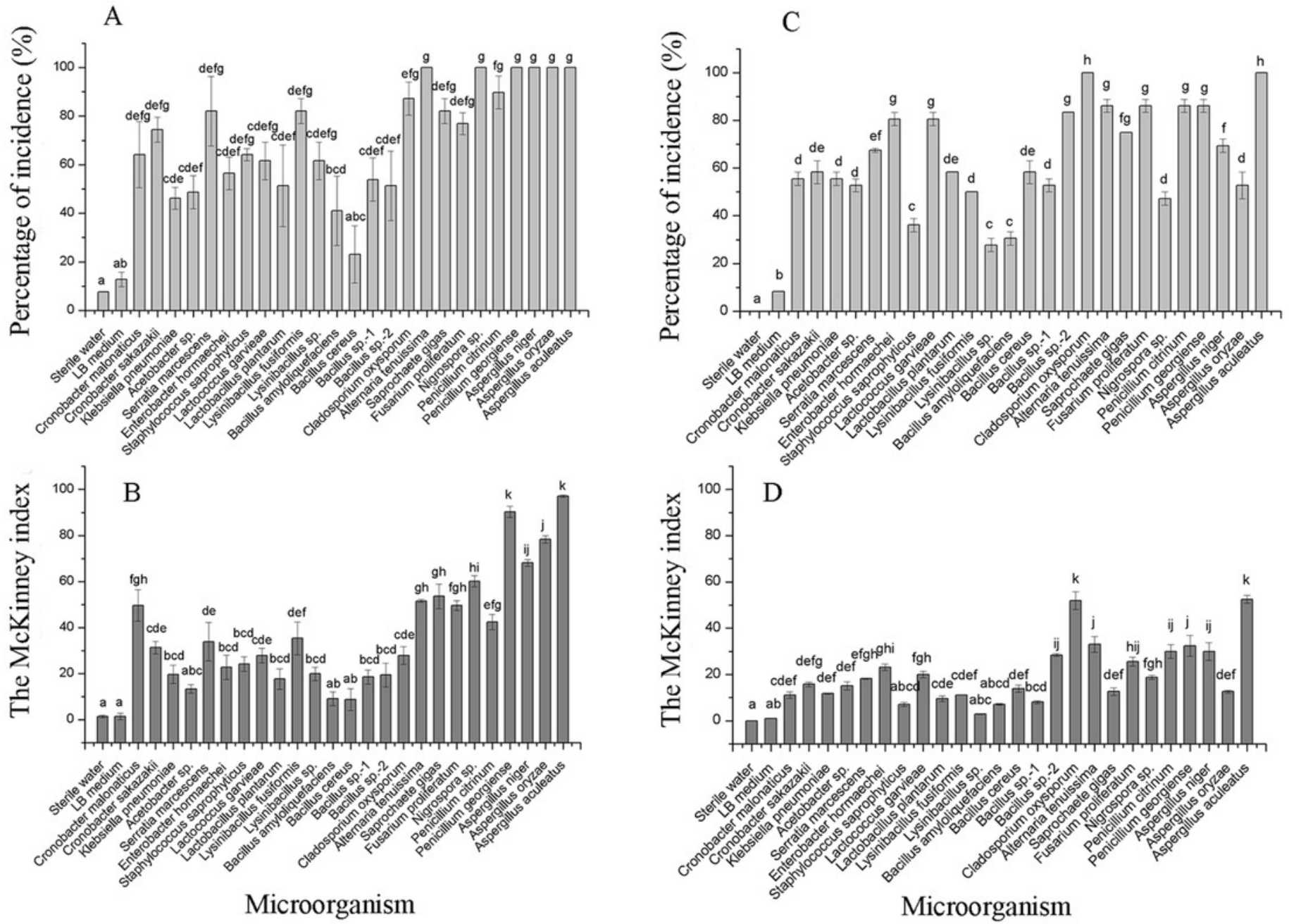